\title{
Impact of COVID-19 pandemic on aircraft noise levels, annoyance, and health effects in an urban area in Oman
}

\author{
Patrick Amoatey ${ }^{1} \cdot$ Issa Al-Harthy $^{1} \cdot$ Khalifa Al-Jabri $^{1} \cdot$ Abdullah Al-Mamun $^{1} \cdot$ Mahad Said Baawain $^{2}$. \\ Ahmed Al-Mayahi ${ }^{3}$
}

Received: 2 April 2021 / Accepted: 9 November 2021 / Published online: 22 November 2021

(c) The Author(s), under exclusive licence to Springer-Verlag GmbH Germany, part of Springer Nature 2021

\begin{abstract}
This study aimed at investigating aircraft noise exposure levels, their annoyance, and potential health effects among communities living within airport catchment areas during the COVID-19 pandemic. Both field measurements and an online survey approach were used to investigate aircraft noise exposure levels, annoyance, and general health effects among residents living near Muscat International Airport (MCT) in Muscat, Oman, amid the COVID-19 period. The study found a drastic decline in aircraft noise levels due to the introduction of COVID-19 intervention measures such as lockdowns, social distancing, and closure of airports. In June 2020, during the COVID-19 pandemic, average daily aircraft noise levels of $\mathrm{L}_{\text {Aeq }}$ (39.9 dB(A)) and $\mathrm{L}_{\max }(49.7 \mathrm{~dB}(\mathrm{~A})$ ) was observed compared to the previous year (April-May 2019) of 58.5 and $76.8 \mathrm{~dB}(\mathrm{~A})$, indicating aircraft noise reductions level of $32 \%$ and $35 \%$, respectively. The results of the online social survey among 187 participants showed that most $(58.8 \%)$ of the respondents did not feel that the level of noise produced by aircraft causes annoyance. During the day, the vast majority of the interviewees did not complain of any annoyance during the morning $(45.5 \%)$, afternoon $(39.6 \%)$, and evening $(31 \%)$ with only $<4 \%$ of residents have reported a very high degree of annoyance of during COVID-19 pandemic period. Very few people (17\%) did complain of experiencing general health problems while $29 \%$ did not know of any potential health effects that could be attributed to aircraft noise exposures. Aircraft noise annoyance complaints among the As-Seeb residents during the pre-COVID-19 pandemic periods were reported to be extremely high reaching about $84 \%$ compared to $41 \%$ during this current COVID-19 pandemic period. These findings support the need to develop future sustainable noise mitigation policies in order to help reduce noise exposures and improve human health during post-COVID-19 pandemic periods.
\end{abstract}

Keywords COVID-19 $\cdot$ Aircraft noise $\cdot$ Annoyance $\cdot$ Health effects $\cdot$ Muscat $\cdot$ Oman

Responsible Editor: Philippe Garrigues

Issa Al-Harthy

aissa@squ.edu.om

1 Department of Civil and Architectural Engineering, College of Engineering, Sultan Qaboos University, P.O. Box 33, Al-Khoudh P.C. 123, Muscat, Sultanate of Oman

2 Ministry of Labour, P.O. Box 413, PC 100, Muscat, Oman

3 Department of Soils, Water and Agricultural Engineering, College of Agriculture and Marine Sciences, Sultan Qaboos University, P.O. Box 34, Al-Khoudh P.C. 123, Muscat, Oman

\section{Introduction}

The health and economic impacts from the COVID-19 pandemic have been exacerbated mainly due to the introduction of stringent lockdown measures by several countries which have ultimately affected the global business cycles (Guan et al. 2020; Ozili and Arun 2020). Fortunately, the COVID19 lockdown and social distancing measures have positively impacted environmental pollution levels through a reduction in noise, air, and water pollution including lesser flooding events in most countries (Lokhandwala and Gautam 2020; Muhammad et al. 2020).

It is widely known that the COVID-19 pandemic has affected the aviation industry due to the closure of several airports across the world. This has greatly affected the mobility of many travelers and has also caused an economic 
loss to thousands of aviation industries. Fortunately, the COVID-19 pandemic measures especially the closure of airports have led to a huge reduction in aircraft noise pollution levels among populations living closer to airport areas (Iacus et al. 2020a; Suau-Sanchez et al. 2020). Previous studies showed that noise levels produced by aircraft traffic were associated with an increase in acoustic discomforts including annoyance, irritations, anxiety, and sleep disorders (Beutel et al. 2016; Brink et al. 2019; Lechner et al. 2019; Quehl et al. 2017). A cross-sectional study on the impact of aircraft noise exposures involving a total of 400 adult population of 45-70 years of age was carried out in Italy (Carugno et al. 2018). It was reported that annoyance levels among residents (65-76 dBA) living closer to the airports were doubled compared to those individuals (60-65 dBA) in far distant areas. Also, complaints about sleep disorders were found to be $36 \%$ and 30\%, among the residents of areas closer to the airports and far distant areas, respectively (Carugno et al. 2018). A meta-analysis study comprising of more than 16,000 residents found an association with aircraft noise levels and an increase in the incidence of hypertension, especially among women and those with more than 55 years of age following the subgroup analysis (Huang et al. 2015). It was concluded that aircraft noise levels could lead to the prevalence of cardiovascular diseases (Huang et al. 2015). Similarly, there has been evidence of an increase in hospital admissions (Correia et al. 2013) and symptoms of cardiovascular diseases as a result of frequent exposure to high aircraft noise levels (Azuma and Uchiyama 2017). There have been situations of increased in symptoms of heart diseases and the incidence of stroke among people living closer to airports in many European countries following long-term airport noise exposures (Floud et al. 2013).

With regard to the impact of the COVID-19 pandemic on noise levels, there have been dramatic quieting of seismic noise levels in several cities across the world due to the effect of COVID-19 public health intervention measures especially lockdowns, restricted industrial, commercial, and road/air transport activities (Lecocq et al. 2020). During the 41-day lockdown in Milan, Italy, an empirical study using stationary noise monitoring systems revealed a drastic reduction of population exposure to urban noise levels by $6 \mathrm{dBA}$ with anomalous noise events being identified as the main contributors during the pandemic (Zambon et al. 2021). In Kanpur city of India, there was a significant decrease in average noise levels during the lockdown $(57.7 \mathrm{~dB})$ period compared to the pre-COVID era of $79.5 \mathrm{~dB}$. These improved acoustic situation levels translated into a low predicted annoyance level of $41.2 \%$ and $50.2 \%$ during the lockdown period compared to the pre-lockdown periods of $86 \%$ and $87 \%$ in residential and near industrial areas, respectively (Mishra et al. 2021). It should be noted the noise levels during the pandemic were generally low, but a study has found that it was far lower in hotspots areas such as airports and major central areas of cities than the distant suburbs (Basu et al. 2021).

The pandemic did not only affect residential noise levels but rather several protected vegetation areas as well. In Boston USA, it was reported that there were lower $(1-3 \mathrm{~dB})$ noise levels around parks situated further away from major roads than those located alongside the urban roads of 4-6 dB during the COVID-19 pandemic in March-June 2020 (Terry et al. 2021). Others have indicated that acoustic environments have been improved during festival celebrations compared to the pre-pandemic noise levels following the implementation of the COVID-19 prevention protocols in some towns in India (Kalawapudi et al. 2021). Such observed quiet residential environment caused by the pandemic led to positive reactions of people towards low noise levels in their neighborhoods, especially in both indoor and outdoor environments. The study found that even the most vulnerable group ( $>60$ years) was able to detect low indoor noise levels during the pandemic (Caniato et al. 2021).

Over the decades, populations especially those dwelling near airports' areas were continuously exposed to noise levels with their attendant annoyance and health-related problems (Evrard et al. 2015; Eze et al. 2020; Franssen et al. 2004; Hansell et al. 2013; Lefèvre et al. 2020). Thus, very studies has assessed so far aircraft noise levels, annoyance, and health effects over several months during airport closures from the COVID-19 pandemic through a social survey. Considering the effect of noise on the health and well-being of the exposed population, it is crucial to evaluate the degree of noise exposure levels among resident populations living nearer to airport areas as a result of the impact of COVID-19 lockdowns and social distancing measures. This study aimed to assess aircraft noise exposure levels and the extent of annoyance among residents living closer to Muscat International Airport (MCT), in Oman, amid the COVID-19 pandemic period when the lockdown measures were in place. In doing so, both field measurements and online social survey approaches were employed to, respectively, estimate noise and annoyance levels among the exposed population. It is believed that these studies could provide background noise data for future noise mitigation measures which could aid in addressing the burden of noise-related health problems. Furthermore, the study outcomes could be used as a proxy in understanding aircraft noise pollution and annoyance levels in other countries across the globe during the current COVID-19 pandemic period.

\section{Research data and methodology}

\section{Study area}

This study was conducted in the As-Seeb district area within Muscat Governorate, Sultanate of Oman. As-Seeb City has 
a total resident population of 463,960 people representing more than $32 \%$ of the entire population of Muscat $(\sim 1.42$ million) (NCSI 2020). The climate in As-Seeb is characterized by short winter (December-February) and long summer (June-September) seasons with average ambient air temperature ranging from $16.7{ }^{\circ} \mathrm{C}$ to a maximum of $40{ }^{\circ} \mathrm{C}$, respectively. Rainfall is rare and normally occurs in winter with a maximum level of $16.5 \mathrm{~mm}$; however, outdoor humidity levels have always been consistent at $15 \%$ to $>90 \%$ depending on the season (DGM 2020). As-Seeb is one of the major commercial and business hubs of Oman due to its closer proximity to the Muscat International Airport (MCT) making it one of the hotspots of high aircraft noise impacted areas in Muscat (Al Harthy 2007). The detailed description of the study area including measured noise locations and MCT is shown in Fig. 1.

\section{Data}

\section{COVID-19 status}

Following the SAR-COV-2 virus outbreak in Wuhan city of China, Oman reported its first two (2) COVID-19 cases in Muscat on 24 February 2020 due to previous travels from Iran. On 25 March 2020, MCT was closed for commercial scheduled flights except for exempted activities such as medical supplies, evacuations of Omani citizens, etc. However, after 5 April, the country started experiencing a rapid increase in the daily number of COVID-19 cases in its major cities especially in Muscat including As-Seeb. These high cases led to more stringent interventions such as lockdowns, closure of schools and mosques, implementation of social distancing measures, reduction in the number of workers by $30 \%$, and implementation of wearing a facial mask in all public places (Khamis et al. 2020). As of 14 September 2020 3:32 PM CEST, the total confirmed cases of Oman remain 89,746 with $>93 \%$ recoveries. The number of COVID-19 deaths and sick people currently remains at 780 and 5195 cases, respectively, according to the Oman Ministry of Health (2020) and WHO (2020) as in June 2020. Table 1 shows the top six (6) governorates with high COVID-19 cases including Muscat where As-Seeb city is located. The data clearly shows that Muscat has the highest cases representing almost $50 \%$ of the total national COVID19 cases compared to other governorates. It should be noted that this current noise exposure assessment was conducted during June 2020 when the Oman was embarking on several public health interventions such as lockdowns and closure of airports. The COVID-19 cases of Oman as of August 2021 presented in Table 1, is aimed at providing the current COVID-19 situations during the peak of the pandemic and, also when the country has achieved greater success in

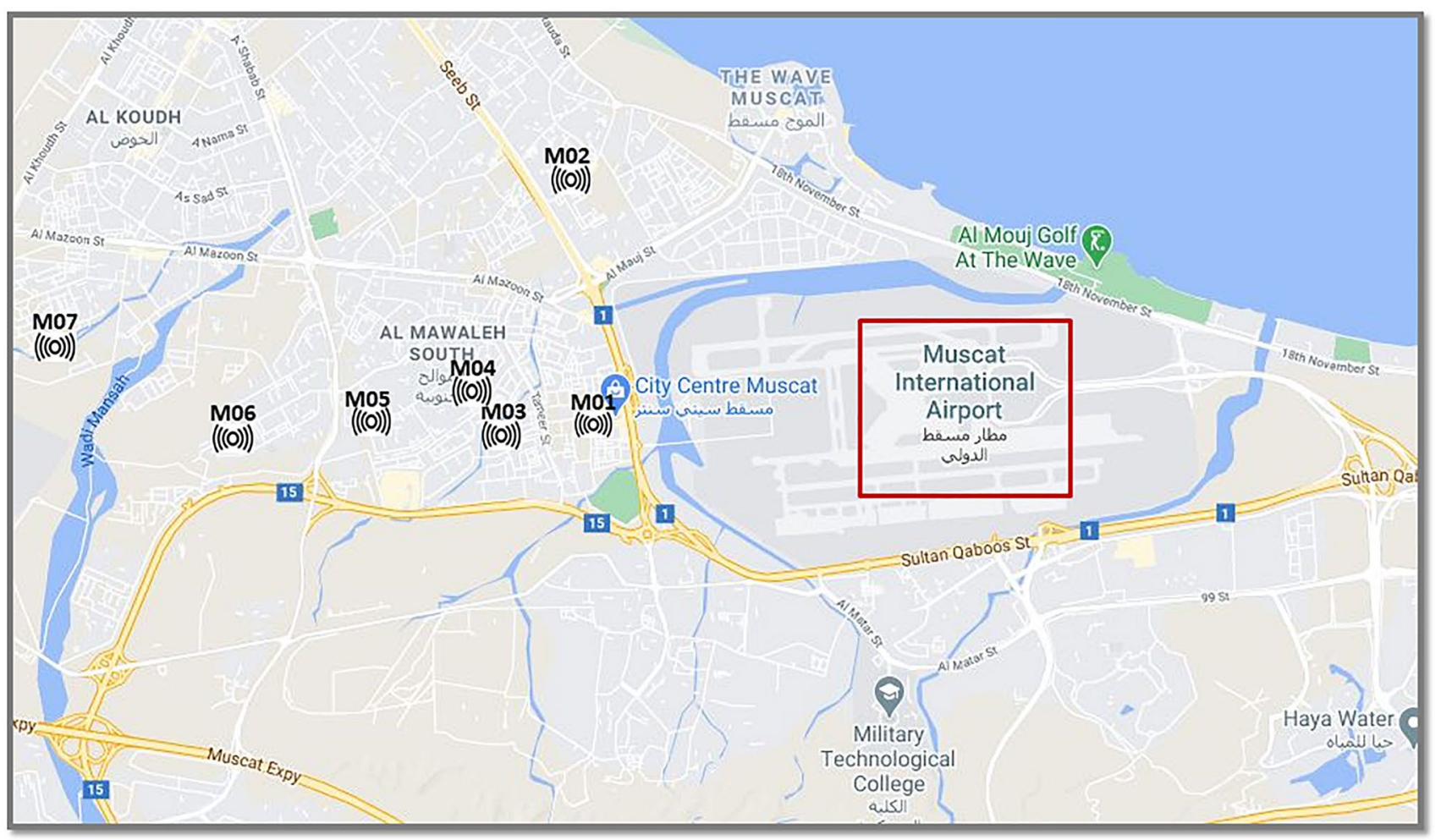

Fig. 1 A map showing the location of the study area and noise measurement points 
Table 1 COVID-19 cases for top six governorates in Oman as of June 2020 when the noise exposure assessment was conducted and as of August 2021 during the peak period of the pandemic and also when about $50 \%$ of the population has received double doses of vaccination

\begin{tabular}{|c|c|c|c|c|c|c|}
\hline \multirow[t]{2}{*}{ Location } & \multicolumn{3}{|c|}{ June 2020} & \multicolumn{3}{|c|}{ August 2021} \\
\hline & Cases & Recovery & Death & Cases & Recovery & Death \\
\hline Muscat (including As-Seeb) & 43,981 & 41,694 & 288 & 150,124 & 146,455 & 1,371 \\
\hline North Batinah & 15,616 & 14,293 & 184 & 44,723 & 42,558 & 826 \\
\hline South Batinah & 10,170 & 9687 & 111 & 26,573 & 25,521 & 446 \\
\hline Al Dakhliyah & 5880 & 5283 & 51 & 19,649 & 19,264 & 370 \\
\hline Dhofar & 3760 & 3221 & 39 & 19,652 & 19,264 & 344 \\
\hline Al Wusta & 1739 & 1664 & 4 & 6,373 & 6,036 & 36 \\
\hline National (Oman) Total & 89,746 & 83,771 & 780 & 303,673 & 296,917 & 4,095 \\
\hline
\end{tabular}

Sources: (Ministry of Health 2020; WHO 2020).

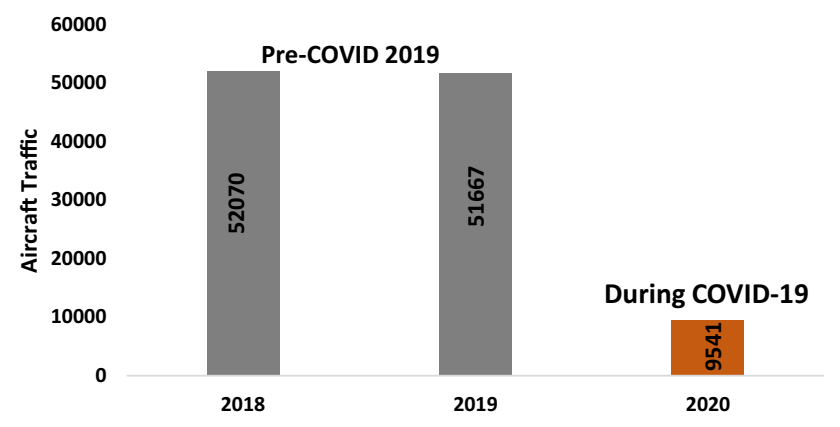

Fig. 2 Aircraft traffic levels at MCT during COVID-19 pandemic (March-July 2020) compared to the same months of the previous years (2018 and 2019), source: PACA (2020)

vaccination of about $50 \%$ double doses of the entire population of Oman.

\section{Aircraft data}

Aircraft (both takeoff and landing) traffic of MCT was acquired from Oman Public Authority for Civil Aviation before and during the COVID-19 pandemic period (PACA 2020). Aircraft traffic data were compared for March-July of the year 2018 and 2019 with March-July 2020 (during the COVI-19 pandemic period) to assess the level of reductions in aircraft traffic at MCT (Fig. 2). Compared to the previous years (2018-2019), it could be observed that there have been more than $80 \%$ reductions in the number of aircraft traffic representing an average of $\sim 42,000$ flights in MCT due to the COVID-19 pandemic. The reported 9,541 flights were mainly due to evacuation activities, domestic movements, and medical-related travels (PACA 2020).

\section{Noise impact assessment}

\section{Field measurements}

Noise data was acquired through field measurements during the COVID-19 pandemic period for 2 days starting 19 to 20 June 2020 using a sound level meter (SLM) (BandK Investigator ${ }^{\mathrm{TM}}$, Model 2260, Denmark). SLM used in this study is rated as a type 1 instrument by both the International Electrotechnical Commission (IEC) and American Standard Institute (ANSI) as an outdoor sound pressure meter with a maximum operating frequency of $20 \mathrm{kHz}$ (Brüel and Kjær 2021). During the measurements, the SLM was installed at a height of $9.4 \mathrm{~m}$ similar to that of most residential story buildings found in the MCT area. A 24-h continuous sound pressure level and A-weighted (LAeq $\mathrm{dB}(\mathrm{A})$ ) noise levels were recorded at seven (7) selected points (M01-M07) randomly located at various residential areas in As-Seeb within a distance of 1.9-4.2 km from the MCT Runway (08L) as shown in Fig. 1. These distances were selected as the most suitable areas of noise measurements as the majority of residential and commercial buildings are found within these ranges and thus may be highly exposed to aircraft noise levels.

\section{Public survey}

Study population and survey procedure A cross-sectional study was conducted by selecting a sample population from adults who are current residents of As-Seeb during the COVID pandemic period, living in closer proximity to the MCT neighborhood, and deemed as being exposed to aircraft noise levels. Based on the likelihood of about $25 \%$ prevalence level of complaint of aircraft-related annoyance and sleep disorders, the sample size of the exposed population was estimated at 95\% confidence intervals (CI) (Paiva et al. 2019; World Health 2011). An online survey through questionnaires was conducted on 26-29 June 2020 to assess the impact of aircraft noise levels among the population amid the COVID-19 pandemic during the lockdown period. As the researchers observed COVID-19 social distancing protocols during the study, the survey questionnaire was administered among Sultan Qaboos University (SQU) staff/ students who are living in the study area using their emails rather than field survey study. Prior consent of the participants was sought by indicating "accept" or "decline" in the emails. The location of the respondents through the google 
navigation tool was confirmed once they indicated that they dwell in the study area (i.e., As Seeb) in the questionnaire. The respondents were informed about the objective of the study and the researcher's credibility was assured since the respondents are already affiliated with the SQU community.

Questionnaire The perception of aircraft noise levels, its annoyance, and health effects were assessed using a 5-point verbal scale similar to International Commission on Biological Effects on Noise (ICBEN) scale (Fields et al. 2001) with metrics "not at all," "low," "moderate," "high" and "very high." Also, health impact-related questions were asked by open-ended verbal marks such as "no," "yes," and "don't know." The study further obtained some basic sociodemographic (i.e., gender and age) data of the participants as well as questions on general sources of noise and duration of annoyance. The questionnaire was designed in both English and Arabic languages since these are the commonly used languages in Oman (see the supplementary material). Futhermore, in order to understand the changes in aircraft noise levels under this current study and pre-COVID-19 pandemic period, previously reported aircraft/airport noise annoyance levels conducted by (Al-Harthy et al. 2021) among the same exposed population in As-Seeb, Oman, from December 2018 to February 2019 ( pre-COVID-19 pandemic period) were used as a proxy.

\section{Data analysis}

All the measured sound pressure levels across the 7 points were expressed as daily (24-h) noise levels, LAeq dB(A), using Excel Software Program version 2016. A descriptive analysis was performed on sociodemographic profile, annoyance, health impacts, and traffic noise source-related responses. Chi-square test using SPSS statistical program, version 23 , was adopted to determine the statistical significance levels with respect to aircraft noise levels and level of annoyance, duration of annoyance, perceived adverse health effects, and traffic noise sources. All Chi-square analyses were conducted at $95 \% \mathrm{CI}$ by adopting statistical significance at an alpha level of 0.05 .

\section{Results}

\section{Noise exposure levels}

24-h sound pressure levels for $\mathrm{LA}_{\mathrm{eq}}$ and $\mathrm{L}_{\max }$ expressed as $\mathrm{dB}(\mathrm{A})$ during the COVID-19 pandemic period (June 2020) are shown in Tables 2 and 3, respectively. During the pandemic, average noise levels $\left(\mathrm{LA}_{\mathrm{eq}}\right)$ within the neighborhood of As-Seeb near MCT was observed to be 37.5-40.6 dB(A), with most of the measured locations having similar median
Table 2 Daily measured aircraft equivalent sound pressure levels $\mathrm{LA}_{\text {eq }}$ expressed as $\mathrm{dB}(\mathrm{A})$ amid COVID-19 pandemic near MCT, Muscat, June 2020

\begin{tabular}{lllll}
\hline $\begin{array}{l}\text { Measured } \\
\text { Points }\end{array}$ & $\begin{array}{l}\text { Average, } \\
\text { dB(A) }\end{array}$ & $\begin{array}{l}\text { Median, } \\
\text { dB(A) }\end{array}$ & $\begin{array}{l}\text { Maxi- } \\
\text { mum, } \\
\text { dB(A) }\end{array}$ & $\begin{array}{l}\text { Mini- } \\
\text { mum, } \\
\text { dB(A) }\end{array}$ \\
\hline M01 & 37.5 & 38.0 & 44.0 & 32.0 \\
M02 & 39.4 & 40.0 & 44.0 & 33.0 \\
M03 & 40.6 & 41.0 & 46.0 & 34.0 \\
M04 & 40.7 & 41.5 & 49.0 & 30.0 \\
M05 & 39.2 & 39.5 & 47.0 & 32.0 \\
M06 & 40.1 & 40.0 & 45.0 & 35.0 \\
M07 & 40.6 & 40.0 & 49.0 & 32.0 \\
\hline
\end{tabular}

Table 3 Daily measured aircraft maximum sound pressure levels $\mathrm{L}_{\text {max }}$ expressed as $\mathrm{dB}(\mathrm{A})$ amid COVID-19 pandemic near MCT, Muscat, June 2020

\begin{tabular}{lllll}
\hline $\begin{array}{l}\text { Measured } \\
\text { points }\end{array}$ & $\begin{array}{l}\text { Average, } \\
\mathrm{dB}(\mathrm{A})\end{array}$ & $\begin{array}{l}\text { Median, } \\
\mathrm{dB}(\mathrm{A})\end{array}$ & $\begin{array}{l}\text { Maxi- } \\
\text { mum, } \\
\mathrm{dB}(\mathrm{A})\end{array}$ & $\begin{array}{l}\text { Mini- } \\
\text { mum, } \\
\mathrm{dB}(\mathrm{A})\end{array}$ \\
\hline M01 & 47.5 & 46.5 & 60.0 & 38.0 \\
M02 & 46.7 & 45.5 & 58.0 & 37.0 \\
M03 & 49.4 & 48.0 & 60.0 & 40.0 \\
M04 & 51.9 & 54.0 & 60.0 & 41.0 \\
M05 & 51.9 & 53.0 & 59.0 & 43.0 \\
M06 & 48.0 & 47.5 & 58.0 & 38.0 \\
M07 & 46.1 & 47.5 & 54.0 & 37.0 \\
\hline
\end{tabular}

noise levels of about $40 \mathrm{~dB}(\mathrm{~A})$ (Table 2). The minimum sound pressure levels for all the seven (7) measured points were very consistent, and all fell within a range of 30-35 dB(A). Similarly, the daily average $\mathrm{L}_{\max }$ values were found ranging from $46.1-51.9 \mathrm{~dB}(\mathrm{~A})$ within the same locations with maximum and minimum values observed within 37-43 and 44-60 dB(A), respectively (Table 3 ). Thus, during the COVID-19 pandemic period, the daily average noise pollution levels in terms of $\mathrm{LA}_{\mathrm{eq}}$ were found to be more than $10 \mathrm{~dB}(\mathrm{~A})$ lower when compared to WHO's critical limits of $55 \mathrm{~dB}(\mathrm{~A})$ for community noise exposures. In addition, all measured aircraft noise levels $\left(\mathrm{LA}_{\mathrm{eq}}\right)($ Table 2$)$ were below $45 \mathrm{~dB}(\mathrm{~A})$, a more stringent aircraft noise standard recommended by the Guidelines Development Group (GDG) (WHO 2018). These results clearly showed that the COVID19 pandemic has caused a drastic decline in aircraft noise levels in the study area.

A visual representation of hourly (8:00-19:00) sound pressure levels of the 7 selected points (M01-M07) near MCT during the COVID-19 pandemic in terms of LAeq and Lmax is shown in Fig. 2. A slight increase in hourly noise levels was observed in the majority of the points (e.g., M01-M06) during the morning (7:00-16:00), and then later 
they decline after 19:00 and are maintained to constant levels until 4:00. All the measured points experienced an increase in the noise levels again after 5:00. These similar patterns of hourly noise levels across all the points clearly show that the MCT area experienced consistent aircraft traffic levels due to the COVID-19 pandemic. This also implies that the noise levels near MCT were not influenced significantly by other sources such as road traffic, industrial, and neighborhood activities (Fig. 3).

Table 4 shows the differences in observed sound pressure levels between the historical (April-May 2019) and the current (June 2020) COVID-19 pandemic timeframes. It can be found that there was a significant reduction in average aircraft noise $\left(\mathrm{LA}_{\mathrm{eq}}\right)$ levels by more than $32 \%$, representing about $18 \mathrm{~dB}(\mathrm{~A})$ in the same residential area (As-Seeb). A similar pattern was observed for $\mathrm{L}_{\max }$ noise values, where average pre-COVID-19 aircraft noise values of $76.81 \mathrm{~dB}(\mathrm{~A})$ (Al-Harthy et al. 2021) were found to be higher compared to the levels during the COVID-19 period of $49.78 \mathrm{~dB}(\mathrm{~A})$. Overall, the decline of the measured $\mathrm{L}_{\max }$ noise by $35 \%$ or a value of $27 \mathrm{~dB}(\mathrm{~A})$ when compared to the historic aircraft noise levels was very similar to that of $\mathrm{LA}_{\mathrm{eq}}$ values (Table 4). These recorded low aircraft noise levels near the residential areas of MCT confirm a huge reduction in aircraft traffic volumes during the COVID-19 pandemic (March-July 2020) period compared to the previous historic years (March-July 2018-2019) as illustrated in Fig. 2.

\section{Noise impact assessment results}

In overall, 187 participants enrolled in the online survey study during the COVID-19 pandemic period. This represents a response rate of $65 \%$ when compared to the WHO's assumed sample size of $\sim 290$ for the prevalence of reports associated with sleep disorders and annoyances from traffic noise exposures (Amoatey et al. 2020; Paiva et al. 2019). The sample size $(n=187)$ of the respondents under this study is deemed as an adequate representative of the populations in As-Seeb to understand the aircraft noise levels during the COVID-19 pandemic due to several limitations such as lockdowns, quarantine, and local travel restrictions making it difficult to get a large number of people to participate in the survey.

The majority of the respondents $(51.3 \%)$ were within 25-50 years of age with about $29 \%$ having more than 50 years. About 109 of the study participants were female, representing $58.3 \%$, this was slightly higher compared to male (41.7) counterparts (Table 5).

For general community noise levels, very few people representing about $2 \%, 1 \%, 4 \%$, and $6 \%$ viewed that noise levels as very high and are normally from industrial, construction, neighborhood, and road traffic sources, respectively. Most of the participants $(61.5 \%)$ found industrial activities have not been a source of noise at all, with nearly $30 \%$ having the same opinion for the other community noise sources. Aircraft-related noise exposure levels during the COVID19 pandemic were considered by $38.5 \%$ of the respondents as low with few people feeling it as very high. Interestingly, about a quarter of the study participants (24.1\%) believed that aircraft traffic activities during the COVID-19 pandemic do not produce noise at all (Table 5).

Regarding aircraft noise annoyance levels, Table 6 illustrates reported annoyance levels and related health impacts during the COVID-19 pandemic period among the residents who live near MCT. During this period, the majority $(58.8 \%)$ of the respondents did not feel that the level of noise produced by aircraft causes annoyance. The magnitude of the annoyance was reported to be slightly by the greater proportion $(33.7 \%)$ of the residents with about $28.3 \%$ people considering it as not causing annoyance at all. However, very few $(15.5 \%)$ respondents deemed the current aircraft noise levels amid the COVID-19 pandemic as causing extreme annoyance. It was also found that the majority of the respondents did not complain of any annoyance during the morning (45.5\%), afternoon (39.6\%), and evening (31\%). Only about $12 \%$ of the participants considered the aircraft noise exposures as high especially during the afternoon and evening time of the day. However, less than $4 \%$ of residents reported a very high degree of annoyance during this COVID-19 pandemic period. With regard to potential health impact, more than half of the participants $(53.4 \%)$ stated that they did not experience any adverse health effects due to aircraft noise levels during the current COVID-19 pandemic period. Very few respondents of nearly $18 \%$ did report experiencing general health problems while $29 \%$ did not know of any health effects caused by aircraft noise levels during the COVID-19 pandemic period (Table 6). The study also found a statistical significance among As-Seeb dwellers who have been exposed to aircraft noise levels during the COVID-19 pandemic period and feeling of annoyance $(p<0.016)$ and the degree of noise annoyance $(p<0.003)$ and time (morning, afternoon, evening) of the annoyance during the day. It was also found that the perception about the potential health effects of aircraft noise exposure levels during the COVID-19 pandemic among the respondents was significant $(p<0.001)$ (Table 6).

\section{Changes in noise annoyance levels during and before the COVID-19 pandemic}

To better understand the effect of the COVID-19 on aircraft noise levels in As-Seeb Oman, it is imperative to evaluate the current noise annoyance levels presented in Table 6 and compare them with the baseline noise annoyance levels during the pre-COVID-19 pandemic period. It should be noted that there is no counterfactual of the 


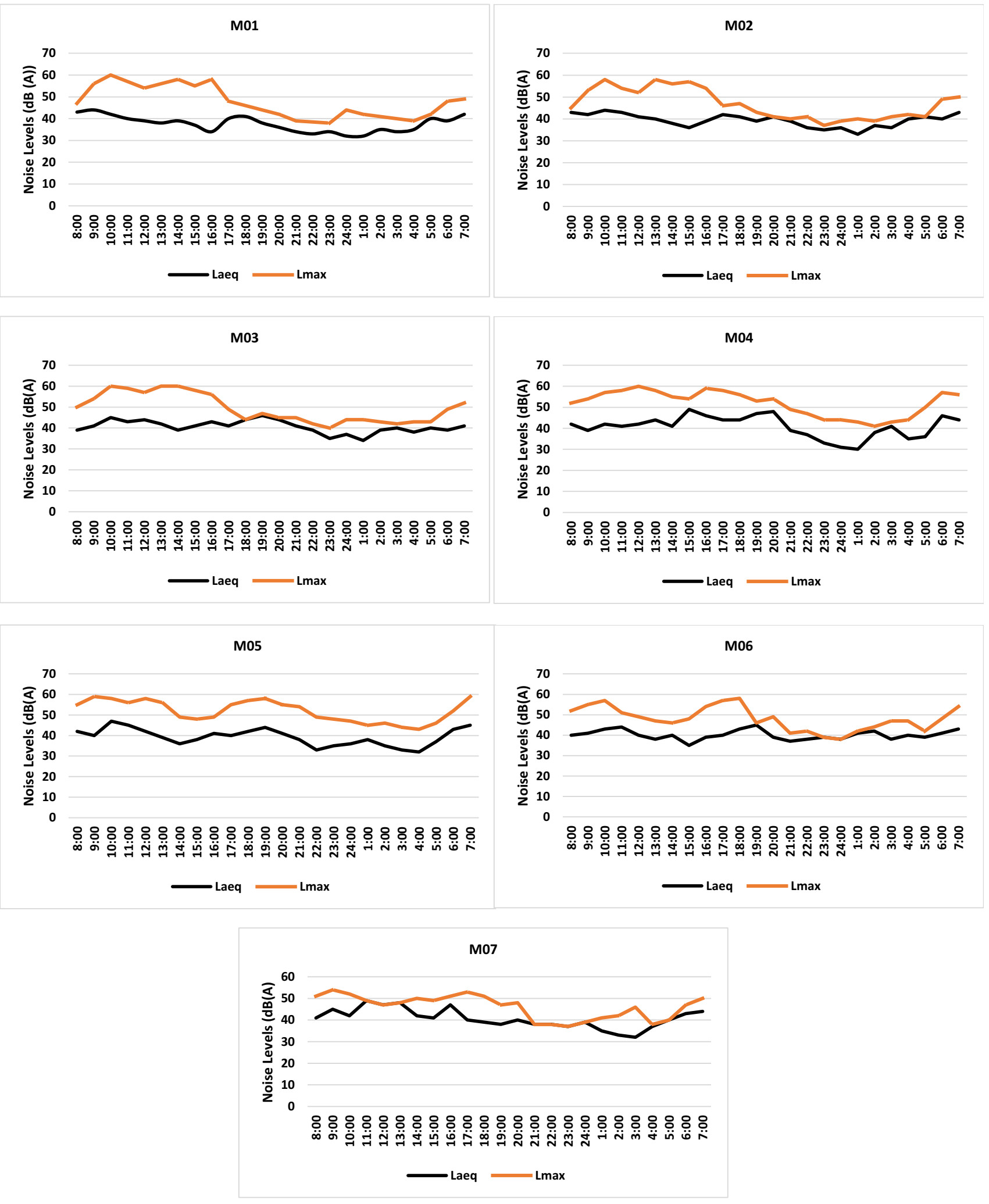

Fig. 3 Hourly noise levels $\left(\mathrm{L}_{\text {Aeq }}, \mathrm{L}_{\max }\right)$ near MCT, Muscat amid COVID-19 pandemic 
Table 4 Aircraft noise levels of current and historical durations measured near MCT, Muscat of Oman COVID-19 pandemic for average daily $\mathrm{L}_{\text {Aeq }}$ and $\mathrm{L}_{\max }$ in $\mathrm{dB}(\mathrm{A})$

\begin{tabular}{llll}
\hline Measured noise & $\begin{array}{l}\text { Current } \\
(\text { June 2020) mean (SD) }\end{array}$ & $\begin{array}{l}\text { Historical } \\
\text { (April-May 2019) } \\
\text { mean (SD) }\end{array}$ & Differences (\%change) \\
\hline $\mathrm{LA}_{\mathrm{eq}}$ & $39.72(1.15)$ & $58.55(3.81)$ & $-18.83(-32.16 \%)$ \\
$\mathrm{L}_{\max }$ & $49.78(2.36)$ & $76.81(5.42)$ & $-27.03(-35.19 \%)$ \\
\hline
\end{tabular}

The historical noise levels were acquired from Al-Harthy et al. (2021). The historical (measured in AprilMay 2019) and the current noise (measured in June 2020) levels consisted of 15 and 7 measured points, respectively. $\mathrm{SD}$, standard deviation.
Table 5 Sociodemographic features and perception of noise sources during the COVID-19 pandemic were reported by residents living closer proximity to MCT in Muscat, Oman, June $2020(n=187)$

\begin{tabular}{|c|c|c|c|}
\hline Variable & $n$ & $\%$ & $p$ value $*$ \\
\hline Gender & & & 0.023 \\
\hline Male & 78 & 41.7 & \\
\hline Female & 109 & 58.3 & \\
\hline Age (years) & & & $<0.001$ \\
\hline$<25$ & 37 & 19.8 & \\
\hline $25-50$ & 96 & 51.3 & \\
\hline$>50$ & 55 & 28.9 & \\
\hline \multicolumn{4}{|c|}{ Sources of Noise at home } \\
\hline Industrial noise & & & $<0.001$ \\
\hline Not at all & 115 & 61.5 & \\
\hline Low & 55 & 29.4 & \\
\hline Moderate & 9 & 4.8 & \\
\hline High & 4 & 2.1 & \\
\hline Very high & 4 & 2.1 & \\
\hline Construction noise & & & $<0.001$ \\
\hline Not at all & 68 & 36.4 & \\
\hline Low & 65 & 34.8 & \\
\hline Moderate & 41 & 21.9 & \\
\hline High & 11 & 5.9 & \\
\hline Very high & 02 & 1.1 & \\
\hline Neighborhood & & & $<0.001$ \\
\hline Not at all & 73 & 39 & \\
\hline Low & 78 & 41.7 & \\
\hline Moderate & 22 & 11.8 & \\
\hline High & 07 & 3.7 & \\
\hline Very high & 07 & 3.7 & \\
\hline Road traffic & & & $<0.001$ \\
\hline Not at all & 70 & 37.4 & \\
\hline Low & 57 & 30.5 & \\
\hline Moderate & 33 & 17.6 & \\
\hline High & 15 & 8.0 & \\
\hline Very high & 12 & 6.4 & \\
\hline Aircraft & & & $<0.001$ \\
\hline Not at all & 45 & 24.1 & \\
\hline Low & 72 & 38.5 & \\
\hline Moderate & 32 & 17.1 & \\
\hline High & 23 & 12.3 & \\
\hline Very high & 15 & 8.0 & \\
\hline
\end{tabular}

Table 6 Aircraft noise annoyance levels and related health impacts during COVID-19 pandemic era reported by residents living closer proximity to MCT in Muscat, Oman, June $2020(n=187)$

\begin{tabular}{|c|c|c|c|}
\hline Variable & $n$ & $\%$ & $p$ value $*$ \\
\hline Aircraft annoyance & & & 0.016 \\
\hline Yes & 77 & 41.2 & \\
\hline No & 110 & 58.8 & \\
\hline Degree of aircraft annoyance & & & 0.003 \\
\hline Not at all & 53 & 28.3 & \\
\hline Slightly & 63 & 33.7 & \\
\hline Moderate & 42 & 22.5 & \\
\hline Extremely & 29 & 15.5 & \\
\hline \multicolumn{4}{|l|}{ Duration of annoyance } \\
\hline Morning & & & $<0.001$ \\
\hline Not at all & 85 & 45.5 & \\
\hline Low & 51 & 27.3 & \\
\hline Moderate & 35 & 18.7 & \\
\hline High & 10 & 5.3 & \\
\hline Very high & 06 & 3.2 & \\
\hline Afternoon & & & $<0.001$ \\
\hline Not at all & 74 & 39.6 & \\
\hline Low & 55 & 29.4 & \\
\hline Moderate & 30 & 16.0 & \\
\hline High & 23 & 12.3 & \\
\hline Very high & 05 & 2.7 & \\
\hline Evening & & & $<0.001$ \\
\hline Not at all & 58 & 31 & \\
\hline Low & 57 & 30.5 & \\
\hline Moderate & 41 & 21.9 & \\
\hline High & 24 & 12.8 & \\
\hline Very high & 07 & 3.7 & \\
\hline Health effects from aircraft noise & & & $<0.001$ \\
\hline Yes & 33 & 17.6 & \\
\hline No & 100 & 53.4 & \\
\hline Don't know & 54 & 29.0 & \\
\hline
\end{tabular}

same interviewed persons under this study during the preCOVID-19 situation. However, a previously reported study on aircraft/airport noise annoyance levels conducted by Al-Harthy et al. (2021) among the same exposed population in As-Seeb, Oman, from December 2018 to February 
2019 was used as a proxy (Table 7) for comparison. While this pre-pandemic reported aircraft noise annoyance levels may not come from the same interviewees who participated in this current study, the former number of respondents $(n=876)$ was about $78 \%$ higher than the latter $(n=187)$. This large sample survey size may increase the reliability of the pre-pandemic aircraft noise annoyance responses (Table 7) when evaluated against the annoyance levels obtained under the current study (Table 6) to better understand the effect of the COVID-19 pandemic on noise levels.

By comparing the aircraft noise annoyance levels of the residents of As-Seeb, Oman, during the COVID-19 pandemic (Table 6) and pre-COVID-19 (Table 7) pandemic situations, it is clear that there are significant changes in annoyance posed by aircraft activities to the population. During the pandemic (Table 6), only $41.2 \%$ of the AsSeeb residents complained about noise annoyance. These annoyance levels were extremely low when compared to pre-COVID-19 noise annoyance levels of $84 \%$, which was reported by a total of 876 respondents (Table 7). In the same period (pre-COVID-19), a large proportion of the exposed As-Seeb population reaching about $46 \%$ described the degree of aircraft noise annoyance levels as very high; this complaint was found to have reduced dramatically to only $15.5 \%$ during the COVID-19 pandemic. Only $3 \%$ of the respondents were of the opinion that there is no annoyance caused by aircraft noise during the pre-COVID-19, but this has increased to $28.3 \%$ during the COVID-19 pandemic period (Table 6).

Table 7 Reported pre-COVID-19 pandemic airport noise annoyance perception levels (\%) in As-Seeb, Oman, in December 2018 to February $2019(n=876)$ (Al-Harthy et al. (2021))

\begin{tabular}{lll}
\hline Parameters & $n$ & Response (\%) \\
\hline Perception of aircraft annoyance & & \\
$\quad$ Yes & 740 & 84 \\
$\quad$ No & 136 & 16 \\
Degree of aircraft noise annoyance & & \\
$\quad$ No noise & 27 & 3 \\
Low & 88 & 10 \\
Medium & 120 & 14 \\
High & 235 & 24 \\
$\quad$ Very high & 406 & 46 \\
Degree of neighborhood noise annoyance & & \\
No noise & 241 & 28 \\
Low & 391 & 45 \\
Medium & 167 & 19 \\
High & 44 & 5 \\
$\quad$ Very high & 33 & 4 \\
\hline
\end{tabular}

\section{Discussion of results}

The COVID-19 pandemic has caused serious restrictions in air travels leading to a substantial reduction of about 2.8-3.0 million airline passenger traffic populations and with a revenue loss of US\$ 400 billion as a result of the closure of several international airports across the globe (Iacus et al. 2020b; ICAO 2020). This unprecedented decline in aircraft activities has created positive effects on aircraft noise pollution reductions among populations dwelling closer to airport areas. This current study centered on assessing aircraft noise exposure levels, annoyance, and potential health effects related to aircraft traffic among residents living in close proximity to MCT.

The study observed a significant reduction in noise levels by $32 \%$ and $35 \%$ for $\mathrm{LA}_{\mathrm{eq}}$ and $\mathrm{L}_{\max }$, during the COVID19 pandemic compared to the previous year of 58.5 and $76.8 \mathrm{dBA}$, respectively. This reduction in sound pressure levels is due to a decline in both international and domestic airline traffic levels in Oman during the COVID-19 pandemic. These were also attributed to a reduction in commercial (e.g., in hospitality industries) businesses, mobility of people, and road traffic activities related to the MCT operation, thereby leading to an overall decline in overall community noise levels. The response from the social survey conducted revealed that the majority of the respondents do acknowledge that low noise levels during the COVID-19 were not only attributed to reduced aircraft traffic activities but also the due decline in neighborhood, road traffic, and industrial activities as well. This was mainly due to the lockdowns and social distancing measures introduced by the government of Oman with the overall aim of reducing the spread of COVID-19 infections (Khamis et al. 2020).

Noise annoyance, irritation, and sleep disturbances were recognized as the most common health effects of aircraft noise exposures by several studies that were conducted during the pre-COVID19 pandemic (Baudin et al. 2020; Nassur et al. 2019; Nassur et al. 2018). This study observed very low complaints of noise annoyance levels during all three different (morning, afternoon, and evening) durations of the day among the respondents. This was found to be consistent with low aircraft noise levels measured during the same COVID-19 pandemic period. The previous study conducted by Al-Harthy et al. (2021) before the COVID-19 pandemic reported that the majority of the residents complaining about aircraft noise annoyance were very high reaching about $84 \%$ compared to $41 \%$ during this current COVID-19 pandemic period. This drastic reduction in aircraft noise annoyance among the As-Seeb residents amid this pandemic is crucial to help develop future sustainable noise mitigation policies to improve 
future annoyance levels, when traffic is fully restored. With regard to health impacts, most of the residents are of the opinion that there are low risks of developing health problems during the COVID-19 pandemic owing to low aircraft noise levels within the neighborhood. Thus, there is a high possibility that if the COVID-19 pandemic continues, there will be an improvement in cardiovascular health among the exposed population as the health risk factors such as hypertension and high blood pressure will be reduced due to low aircraft noise levels (Eriksson et al. 2007). It is also feasible that future noise mitigation (e.g., noise barriers, redesigning of airports) programs could yield results by reducing aircraft noise exposure levels, annoyance, and health problems if those noise levels are to decline to the levels observed during the COVID-19 pandemic period. This study has several strengths. Firstly, the real-time aircraft noise levels reported in this study during the COVID-19 pandemic could be utilized as background noise levels since such datasets are limited in neighborhood populations that have been frequently exposed to high aircraft traffic levels. Also, the annoyance levels reported in this study could be used as a baseline indicator when embarking on future noise abatement programs especially during the post-COVID-19 pandemic period. The major limitation associated with this study is due to the lack of high-resolution measured noise and health impact assessment data, as the questionnaire used was biased towards the assessment of annoyance levels with limited knowledge on potential health effects such as sleep disturbance and cardiovascular diseases among the respondents. Also, the study could not enroll a large number of participants which is crucial to better understand the effect of the COVID-19 pandemic on aircraft noise annoyance and health impacts.

\section{Conclusions and recommendations}

This study aimed at assessing aircraft noise exposure levels, annoyance, and potential health effects among residents living in close proximity to MCT during the COVID-19 pandemic period. The outcome of the study revealed a significant reduction in aircraft noise $\left(\mathrm{LA}_{\mathrm{eq}}\right.$ and $\left.\mathrm{L}_{\mathrm{max}}\right)$ levels posed by low aircraft traffic activities during the COVID19 pandemic compared to the pre-pandemic period. The reduced aircraft noise levels have led to an improvement in acoustic discomfort where the majority of the study participants considered the aircraft noise annoyance levels as low with the potential of not causing adverse health effects. It was also found that during the day, the vast majority of the interviewees did not complain of any annoyance during the morning (45.5\%), afternoon (39.6\%), and evening $(31 \%)$ with $<4 \%$ of residents having reported very high degree annoyance during the COVID-19 pandemic period. Only about $17 \%$ did complain of experiencing general health problems while $29 \%$ did not know of any potential health effects that could be attributed to aircraft noise exposures. Aircraft noise annoyance complaints during pre-COVID-19 pandemic periods were reported to be extremely high reaching about $84 \%$ compared to $41 \%$ during the COVID-19 pandemic period. It is expected that this study could be used as a baseline indicator for future noise abatement programs after the COVID-19 pandemic period to help determine at which aircraft noise exposure level is likely to cause low annoyance and health impacts. In addition, this study could be used as a prototype in other populations living in closer proximity to airport areas with reduced aircraft traffic activities due to the COVID-19 pandemic. These findings support the need to further mitigate the current aircraft noise threshold limits in order to improve the acoustic conditions of the exposed populations and reduce noise-related annoyance and improve cardiovascular health problems.

Supplementary Information The online version contains supplementary material available at https://doi.org/10.1007/s11356-021-17514-2.

Author contribution Patrick Amoatey was involved with the conceptualization, methodology, data analysis, and writing of the first draft of the manuscript. Issa Al-Harthy assisted in the conceptualization, methodology, data analysis, provision of resources, review, and editing of the paper. Khalifa Al-Jabri provided funding and assisted in the conceptualization, data analysis, and provision of resources. Abdullah Al-Mamun was involved in the conceptualization, methodology, data analysis, review, and editing of the manuscript. Mahad Said Baawain assisted in the conceptualization, methodology, data analysis, and provision of resources. Ahmed Al-Mayahi was involved in the methodology, data analysis, review, and editing of the paper.

Data availability Not applicable.

\section{Declarations}

Ethics approval and consent to participate The respondents who participated in the online survey first received an option of "accept" or "decline" filling out the questionnaires. Thus, the consent has been sought for those who accepted to participate in this study.

Consent for publication Not applicable.

Conflict of interest The authors declare no competing interests.

\section{References}

Al-Harthy I, Amoatey P, Al-Mamun A, Alabri Z, Baawain MS (2021) Assessment of noise levels and induced annoyance in nearby residential areas of an airport region in Oman. Environ Sci Pollut Res 28:45596-45608. https://doi.org/10.1007/s11356-021-13891-w

Al Harthy IH Aircraft noise levels survey and its effect on residents of Muscat City, Oman. In: Turkish Acoustical Society - 36th 
International Congress and Exhibition on Noise Control Engineering, Inter-Noise 2007 Istanbul, 2007. pp 2781-2790

Amoatey P, Omidvarbona H, Baawain MS, Al-Mayahi A, Al-Mamun A, Al-Harthy I (2020) Exposure assessment to road traffic noise levels and health effects in an arid urban area. Environ Sci Pollut Res 27:35051-35064. https://doi.org/10.1007/ s11356-020-09785-y

Azuma K, Uchiyama I (2017) Association between environmental noise and subjective symptoms related to cardiovascular diseases among elderly individuals in Japan. PLoS ONE 12:e0188236. https://doi.org/10.1371/journal.pone.0188236

Basu B, Murphy E, Molter A, Sarkar Basu A, Sannigrahi S, Belmonte M, Pilla F (2021) Investigating changes in noise pollution due to the COVID-19 lockdown: The case of Dublin. Ireland Sustain Cities Soc 65:102597. https://doi.org/10.1016/j.scs.2020.102597

Baudin C et al (2020) The role of aircraft noise annoyance and noise sensitivity in the association between aircraft noise levels and hypertension risk: results of a pooled analysis from seven European countries. Environ Res 191:110179. https://doi.org/10. 1016/j.envres.2020.110179

Beutel ME et al (2016) Noise Annoyance is associated with depression and anxiety in the general population- the contribution of aircraft noise. PLoS ONE 11:e0155357. https://doi.org/10.1371/journal. pone. 0155357

Bhowmick GD, Dhar D, Nath D, Ghangrekar MM, Banerjee R, Das S, Chatterjee J (2020) Coronavirus disease 2019 (COVID19) outbreak: some serious consequences with urban and rural water cycle. NPJ Clean Water 3:32. https://doi.org/10.1038/ s41545-020-0079-1

Brink M et al (2019) A survey on exposure-response relationships for road, rail, and aircraft noise annoyance: differences between continuous and intermittent noise. Environ Int 125:277-290. https:// doi.org/10.1016/j.envint.2019.01.043

Brüel \& Kjær (2021) Sound level meter/Noise meter Brüel \& Kjær. https://www.bksv.com/en/products/sound-and-vibration-meters/ sound-level-meters-and-vibration-meters. Accessed 04/06/2021

Caniato M, Bettarello F, Gasparella A (2021) Indoor and outdoor noise changes due to the COVID-19 lockdown and their effects on individuals' expectations and preferences. Sci Rep 11:16533. https:// doi.org/10.1038/s41598-021-96098-w

Carugno $\mathrm{M}$ et al (2018) Effects of aircraft noise on annoyance, sleep disorders, and blood pressure among adult residents near the Orio al Serio International Airport (BGY), Italy. Med Lav 109:253263. https://doi.org/10.23749/mdl.v109i4.7271

Chan JF-W et al. (2020) A familial cluster of pneumonia associated with the 2019 novel coronavirus indicating person-to-person transmission: a study of a family cluster. Lancet 395:514-523. https://doi.org/10.1016/S0140-6736(20)30154-9

Correia AW, Peters JL, Levy JI, Melly S, Dominici F (2013) Residential exposure to aircraft noise and hospital admissions for cardiovascular diseases: multi-airport retrospective study. BMJ 347:f5561. https://doi.org/10.1136/bmj.f5561

DGM (2020) Historical data. Directorate general of meteorology (DGM). http://www.met.gov.om/opencms/export/sites/default/ dgman/en/weather-chart/historical-data/. Accessed 15/09/2020

Eriksson C, Rosenlund M, Pershagen G, Hilding A, Ostenson CG, Bluhm G (2007) Aircraft noise and incidence of hypertension. Epidemiology 18:716-721. https://doi.org/10.1097/EDE.0b013 e3181567e77

Evrard AS, Bouaoun L, Champelovier P, Lambert J, Laumon B (2015) Does exposure to aircraft noise increase the mortality from cardiovascular disease in the population living in the vicinity of airports? Results of an ecological study in France. Noise Health 17:328-336. https://doi.org/10.4103/1463-1741.165058

Eze IC et al (2020) Incidence of depression in relation to transportation noise exposure and noise annoyance in the SAPALDIA study. Environ Int 144:106014. https://doi.org/10.1016/j.envint. 2020.106014

Fields JM et al (2001) Standardized general-purpose noise reaction questions for community noise surveys: research and a recommendation. J Sound Vib 242:641-679. https://doi.org/10.1006/ jsvi.2000.3384

Floud S et al (2013) Exposure to aircraft and road traffic noise and associations with heart disease and stroke in six European countries: a cross-sectional study. Environ Health 12:89. https://doi. org/10.1186/1476-069x-12-89

Franssen EA, van Wiechen CM, Nagelkerke NJ, Lebret E (2004) Aircraft noise around a large international airport and its impact on general health and medication use. Occup Environ Med 61:405-413. https://doi.org/10.1136/oem.2002.005488

Guan D et al (2020) Global supply-chain effects of COVID-19 control measures. Nat Hum Behav 4:577-587. https://doi.org/10. 1038/s41562-020-0896-8

Hansell AL et al (2013) Aircraft noise and cardiovascular disease near Heathrow airport in London: small area study. BMJ 347:f5432. https://doi.org/10.1136/bmj.f5432

He G, Pan Y, Tanaka T (2020) The short-term impacts of COVID-19 lockdown on urban air pollution in China. Nat Sustain. https:// doi.org/10.1038/s41893-020-0581-y

Huang D, Song X, Cui Q, Tian J, Wang Q, Yang K (2015) Is there an association between aircraft noise exposure and the incidence of hypertension? A meta-analysis of 16784 participants. Noise Health 17:93-97. https://doi.org/10.4103/1463-1741.153400

Iacus SM, Natale F, Santamaria C, Spyratos S, Vespe M (2020) Estimating and projecting air passenger traffic during the COVID19 coronavirus outbreak and its socio-economic impact. Saf Sci 129:104791. https://doi.org/10.1016/j.ssci.2020.104791

ICAO (2020) Effects of Novel Coronavirus (COVID-19) on Civil Aviation: Economic Impact Analysis. International Civil Aviation Organisation https://www.icao.int/sustainability/ Documents/COVID-19/ICAO_Coronavirus_Econ_Impact.pdf. Accessed 11/10/2020

Kalawapudi K, Singh T, Vijay R, Goyal N, Kumar R (2021) Effects of COVID-19 pandemic on festival celebrations and noise pollution levels. Noise Mapp 8:89-93. https://doi.org/10.1515/ noise-2021-0006

Khamis F, Al Rashidi B, Al-Zakwani I, Al Wahaibi AH, Al Awaidy ST (2020) Epidemiology of COVID-19 infection in Oman: analysis of the first 1304 Cases. Oman Med J 35:e145-e145. https://doi.org/10.5001/omj.2020.60

Lechner C, Schnaiter D, Bose-O'Reilly S (2019) Combined effects of aircraft, rail, and road traffic noise on total noise annoyancea cross-sectional study in innsbruck. Int J Environ Res Public Health 16. https://doi.org/10.3390/ijerph16183504

Lecocq T et al (2020) Global quieting of high-frequency seismic noise due to COVID-19 pandemic lockdown measures. Science 369:1338-1343. https://doi.org/10.1126/science.abd2438

Lefèvre M, Chaumond A, Champelovier P, GiorgisAllemand L, Lambert J, Laumon B, Evrard A-S (2020) Understanding the relationship between air traffic noise exposure and annoyance in populations living near airports in France. Environ Int 144:106058. https://doi.org/10.1016/j.envint.2020.106058

Lokhandwala S, Gautam P (2020) Indirect impact of COVID-19 on environment: a brief study in Indian context. Environ Res 188:109807-109807. https://doi.org/10.1016/j.envres.2020. 109807

Ministry of Health (2020) MOH alert: corona virus disease (COVID19). https://www.moh.gov.om/en/-/moh-alert-corona-virusdisease-covid-1-2. Accessed 15/09/2020

Mishra A, Das S, Singh D, Maurya AK (2021) Effect of COVID-19 lockdown on noise pollution levels in an Indian city: a case 
study of Kanpur. Environ Sci Pollut Res 28:46007-46019. https://doi.org/10.1007/s11356-021-13872-z

Muhammad S, Long X, Salman M (2020) COVID-19 pandemic and environmental pollution: a blessing in disguise? Sci Total Environ 728:138820. https://doi.org/10.1016/j.scitotenv.2020.138820

Nassur A-M et al (2019) The impact of aircraft noise exposure on objective parameters of sleep quality: results of the DEBATS study in France. Sleep Med 54:70-77. https://doi.org/10.1016/j. sleep.2018.10.013

Nassur AM, Lefevre M, Leger D, Laumon B, Evrard AS (2018) The effects of aircraft noise exposure on objective sleep quality: the results of the DEBATS study in France. Rev Epidemiol Sante Publique 66:S330. https://doi.org/10.1016/j.respe.2018.05.248

NCSI (2020) Data portal: population national centre for statistics \& information (NCSI). https://data.gov.om/OMPOP2016/popul ation? indicator $=1000140 \&$ region $=1000010$-total-sultanate $\&$ nationality $=1000010$-omani. Accessed 22/12/2020

Ozili P, Arun T (2020) Spillover of COVID-19: impact on the global economy. SSRN Electron J. https://doi.org/10.2139/ssrn.3562570

PACA (2020) Monthly statistics. Public authority for civil aviation. https://paca.gov.om/. Accessed 15/09/2020

Paiva KM, Cardoso MRA, Zannin PHT (2019) Exposure to road traffic noise: annoyance, perception and associated factors among Brazil's adult population. Sci Total Environ 650:978-986. https:// doi.org/10.1016/j.scitotenv.2018.09.041

Quehl J, Müller U, Mendolia F (2017) Short-term annoyance from nocturnal aircraft noise exposure: results of the NORAH and STRAIN sleep studies. Int Arch Occup Environ Health 90:765778. https://doi.org/10.1007/s00420-017-1238-7

Suau-Sanchez P, Voltes-Dorta A, Cugueró-Escofet N (2020) An early assessment of the impact of COVID-19 on air transport: just another crisis or the end of aviation as we know it? J Transp
Geogr 86:102749-102749. https://doi.org/10.1016/j.jtrangeo. 2020.102749

Terry C, Rothendler M, Zipf L, Dietze MC, Primack RB (2021) Effects of the COVID-19 pandemic on noise pollution in three protected areas in metropolitan Boston (USA). Biol Conserv 256:109039. https://doi.org/10.1016/j.biocon.2021.109039

WHO (2018) Environmental noise guidelines for the European Region World Health Organisation. https://www.euro.who.int/__data/ assets/pdf_file/0008/383921/noise-guidelines-eng.pdf?ua $=1$. Accessed 28/12/2020

WHO (2020) WHO coronavirus disease (COVID-19) dashboard. World Health Organisation https://covid19.who.int/. 15/09/2020

World Health O (2011) Burden of disease from environmental noise: quantification of healthy life years lost in Europe. World Health Organization, Regional Office for Europe

Worldometer (2020) COVID-19 Coronavirus pandemic. Worldometer. https://www.worldometers.info/coronavirus/. Accessed 07/06/2020

Yunus AP, Masago Y, Hijioka Y (2020) COVID-19 and surface water quality: improved lake water quality during the lockdown. Sci Total Environ 731:139012. https://doi.org/10.1016/j.scitotenv. 2020.139012

Zambon G, Confalonieri C, Angelini F, Benocci R (2021) Effects of COVID-19 outbreak on the sound environment of the city of Milan, Italy. Noise Mapp 8:116-128. https://doi.org/10.1515/ noise-2021-0009

Publisher's Note Springer Nature remains neutral with regard to jurisdictional claims in published maps and institutional affiliations. 